\title{
Neolaborism: A Theory of Political Economy on the Value of Human Labor as Opposed to Artificial Labor as the Ultimate Means of the Economy in the XXI Century
}

\author{
Luis F. Copertari \\ Computer Engineering Program, Autonomous University of Zacatecas (UAZ), Zacatecas, México \\ Email: copertari@yahoo.com
}

How to cite this paper: Copertari, L.F. (2017) Neolaborism: A Theory of Political Economy on the Value of Human Labor as Opposed to Artificial Labor as the Ultimate Means of the Economy in the XXI Century. Open Access Library Journal, 4: e3835. https://doi.org/10.4236/oalib.1103835

Received: July 19, 2017

Accepted: August 8, 2017

Published: August 11, 2017

Copyright $\odot 2017$ by author and Open Access Library Inc.

This work is licensed under the Creative Commons Attribution International License (CC BY 4.0).

http://creativecommons.org/licenses/by/4.0/ c) (i) Open Access

\begin{abstract}
Neolaborism is a theory that can easily be applied in political economy explaining the value of the economies as a function of the salaries and profit paid and received, respectively. Neolaborism can be defined as the idea that only through the increases in salaries and profits received tied to increases in productivity at least as large as those increases in salaries and profits the economy can grow. Such productivity increases may be due to the successful application of Artificial Intelligence (AI). It is postulated that only the workforce gives value to the economy and a practical way to increase salaries and profit without creating inflation by the use and application of the new technologies of AI is presented. It is also worth mentioning that applying AI without proper care could lead to the destruction of capitalism. Thus, it is crucial, now more than ever, to consider the perspectives of neolaborism when elaborating constructive economic policy in the XXI century.
\end{abstract}

\section{Subject Areas \\ Political Economy}

\section{Keywords}

Neolaborism, Economy, Workforce, Profit, Artificial Intelligence,

Productivity

\section{Introduction}

Neolaborism holds that the only thing that really counts in an economy is the 
value aggregated of all the workforce and profit paid and received in any given economic system. Ideas related to labor and the value of labor were introduced by the classic economist David Ricardo [1]. However, these ideas are developed here from the point of view of XXI century capitalism and providing new ideas and perspectives. These new perspectives constitute a new way to approach our social and academic point of view about labor and it generalizes the concept of labor to not only the typical white-collar or blue-collar workers, but also the business person and/or entrepreneur.

Consider, for example, the sales price to the consumer $(\mathrm{P})$, which is a measure of the real value given by the economy of any good or service. Which parts typically compose such price? The total amount of the sales price includes workforce $(\mathrm{W})$, raw materials $(\mathrm{R})$, investment plus profit $(\mathrm{I})$ and taxes $(\mathrm{T})$. These elements are graphically illustrated in Figure 1, which has been created specifically for the purposes of this paper.

What is of interest for analysis is not only the price of any given good or service (although we start the discussion with this simple example) but rather the whole chain of all the goods and services produced in any given economy, and not only those goods or services linked as inputs to some particular good or service, but the aggregated value of all goods and services of the economy.

As can be seen in Figure 1, the sales price to the public $(\mathrm{P})$ is equal to the sum of all of its components, as indicated by Equation (1).

$$
P=W+R+I+T
$$

However, each of these four components can be expressed in terms of a weight of the sales price. In the case of the workforce such weight is $w$, for raw materials it is $r$, for investment plus profit it is $i$, and for taxes it is $t$. Thus, Equation (1) becomes Equation (2).

$$
P=w P+r P+i P+t P=(w+r+i+t) P
$$

Clearly, Equation (3) must be obeyed so that Equations (1) and (2) are coherent, that is, these four elements constitute $100 \%$ of the sales price to the public of such good or service. (Notice that in principle there can be negative weights,
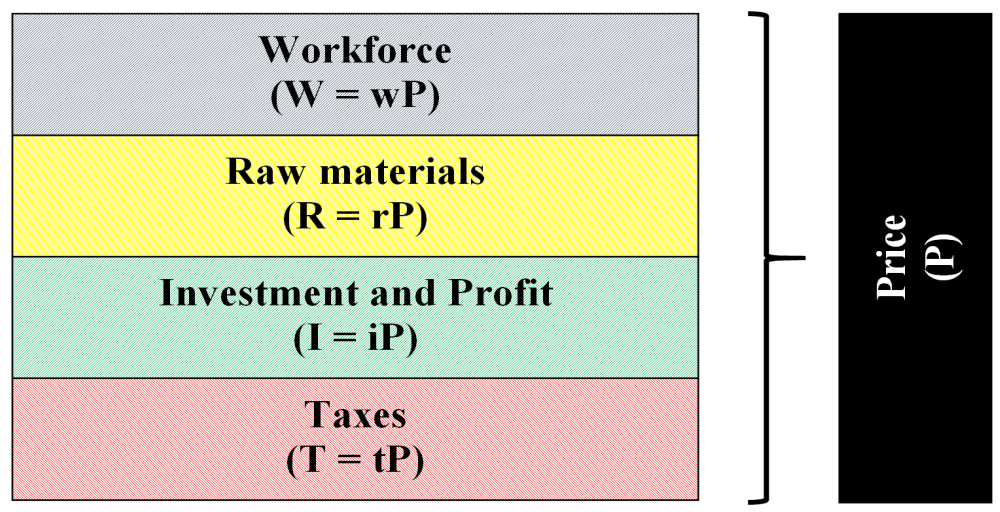

Figure 1. Elements that typically compose the sales price of a good or service. 
as it would be the case for $t$ if, for example, there is a substantial enough governmental subsidy.)

$$
w+r+i+t=1
$$

Each of the four elements that compose the sales price are briefly explained as follows.

Workforce $(\mathrm{W}=\mathrm{wP})$ : It is the total amount for the tangible and intangible work carried out in order to produce such good or service.

Raw materials $(R=r P)$ : It is the value of the set of inputs required to produce such good or service. It can fundamentally be classified in two types:

Price of the cost of other goods and services required.

Cost of extracting the natural resources required to produce such good or service.

Investment and Profit ( $\mathrm{I}=\mathrm{iP}$ ): It is the value of the sales price that the entrepreneur charges for management over the creation and commercialization of such good or service, commonly called profit, and it also includes the cost of the capital invested to produce such good or service per unit being considered (being that investment intellectual capital, financial or any other).

Taxes $(T=t P)$ : It is the value of the sales price that the government charges for the right to sell the good or service.

The main argument of this theory is that it is possible, in the end, to track all of the value of any good or service throughout its productive chain to a series of payments in workforce, being the latter of one kind or another.

How is this possible? Let us see. It is all a matter of tracking each and every one of the previously described elements of the final sales price to the public of each good and service produced in any given economy.

The cost of the weight of the price paid for the workforce is self-explicative, since it is precisely labor. However, the case of the weight paid for raw materials is not so clear. Consider, first, the case of the purchase of all those inputs, tangible or intangible, being goods or services, required to produce any given product or service. Each and every one of these goods or services also have a percentage distribution in its value or cost of workforce, raw materials, investment plus profit and taxes. If we begin by assuming (to be explained later) that all these other components, that is, investment plus profit and taxes, can also be explained as one form of labor or another, the raw material is split in a series of values to finally reach that raw material that it is the result of an extractive activity of natural resources, so that, finally, the value of any given good or service in an economy is the result of all the costs paid for the labor in order to reach, in the end, such good or service.

But, what happens with the raw material, here called final raw material, that is the result of an extractive activity? As it turns out, in order to extract such final raw material, the supplier of the raw material requires workforce, investment (in the form of profit over the investment and investment itself) and a payment, typically to the government (so that the latter can be simply considered another 
tax), to have the "right" to extract such natural resource. The investment for the extractive activity of the raw material, typically translated into machinery, is nothing but the result of purchasing other goods and services that, according to the precepts of this theory, is the result, in the end, of paying labor of one kind or another. Notice that such investment refers to typical machinery, not to entire or partial production systems based on Artificial Intelligence (AI), which would completely change the arguments and places the production system itself in crisis, due to reasons that will be explained in further sections.

The case for investment and profit can be considered a form of salary, no matter how high it might be, that the entrepreneur charges for his(her) talent, economic activity and risk when investing in the production of such good or service plus the investment itself. The fact that investment in itself can be constituted by whole or partial AI systems is precisely the problematic this theory intends to solve, since AI systems do not charge a salary nor they spend money in the economy and that is, precisely, what is increasingly putting pressure on the productive systems of the world and capitalism itself. The gap that exists between the workforce paid to the average worker, technological personnel highly specialized and the entrepreneur is the subject of a whole section below.

Finally, the case of taxes is a little bit complicated to explain. Typically, all the money that the government obtains as taxes and other quotas goes to governmental spending, which essentially translates into a series of purchases of goods and services, which directly enters the hierarchy of costs for workforce, of one or other kind, here proposed. However, if the government does not spend the totality of the value of its coffers and "invests" them in one or other kind of financial instrument, we get into the issue of speculative spending, which will be addressed in a section below.

\section{The Income Gap}

Stiglitz [2] carefully explains the enormous income gap that exists between those that make the most money and those that make the least. The fact that today exists such a great income gap, should it worry us? According to Friedman [3], the argument that different people make different amounts of money is due to the fact that they possess different merits. The more talented and skillful people move (and manipulate?) the system, which explains such abysmal difference in the incomes of people.

According to Stiglitz [2] such gap is not due to the skills of some with respect to others, but rather to the fact that the powerful arrange the rules of the game to their benefit.

From the point of view of this theory, there is no problem at all in having income gaps among people, except for one very important issue: what do these people do with that money?

If the answer is spending it in its entirety, as is the case of those who earn less, since they have no other thing to do with the money but to spend it, with any 
luck, to barely be enough for their day to day spending, there is no problem, since the money goes back to the economy, being destined to the purchase of goods and services, which directly enters the value chain of the economy.

If the answer is, on the contrary, to save it, the question becomes: what do these people do with their money saved? If the answer is reinvesting it in its entirety in the economy, there is also no problem, since the money goes back into the productive economy. However, if the answer is to put it on the speculative pile of capital that never gets reinvested and goes from place to place in a frenetic (and finally useless) attempt to achieve speculative rents, there is a problem.

\section{Speculative Capitalism}

The problem with speculative capitalism is that the basic assumption made is that such capital will eventually be invested in the productive economy. Yet even worse, is the fact that it implicitly assumes that capital generates returns over the investment exponentially, that is, returns over the capital plus all accumulated previous interests are obtained in each period of time. Copertari [4] shows in a mathematical and algorithmic experiment that such assumption is not correct, not even with a change in paradigm, as Kurzweil assumes [5].

Varoufakis [6] highlights the fact that capitalism is not synonym with democracy. The Chinese have proven so widely enough. Varoufakis talks about the twin peaks paradox: the big mountain of debt and its twin, a mountain of idle cash that does not get invested because investors cannot invest it in the productive economy. The combined economies of the USA, England and the Eurozone have invested 3.4 trillion dollars in the first three months of 2015. However, this figure pales in comparison with the debt generated by the three governments: 5.1 trillion dollars in the same period of time. The problem is that the speculative money does not get invested in order to be able to pay the accumulated debt, because investors are too afraid of investing such money. Instead it stays idle in the financial system doing nothing but inflate stock prices and increasing real estate values.

This is the big challenge of the speculative economy: to expect exponential returns over an investment that sits in cash and never truly gets invested in the productive economy. Since the money is never invested in the productive economy, it never becomes a part of the economic system and, as a consequence, it has no real effect in the wealth of nations.

\section{The Concentration of Wealth and Technology}

One of the arguments derived from the analysis of the work carried out by Marx [7] is related to the gradual acceleration of the processes of the generation of new goods and services. As technology progresses, it is possible to innovate faster and faster in the creation of goods and services. This brings about the problem that companies could not recover their investment in the launch of a product if competitors are already launching new products and services that make the 
products of the original company obsolete before even having enough time to recover their investment.

Capitalism has responded, in a very effective way to this problematic, by having a great level of concentration of wealth and technology (which is applied knowledge, typically manifested through patents), in such way that there is only one player or at most a few transnational corporations taking care of the production (or at least the control of the production) of any given good or service. In this way, despite the fact that, at the moment of launching a new product or service, the company already has its replacement, they delay launching such replacement until they have recovered, with profit, the investment made in the original product or service.

This can be clearly observed in the case of the electronic industry when it comes to information storage. Initially and during a considerable number of years VCR-type videocassettes (that quickly replaced the Beta format) were used and also floppies (first 5 1/4 inches and then $3 \frac{1}{1 / 2}$ inches). Then CD-ROM were used, which after a few years were replaced by DVD-ROM and finally BluRay discs. However, computers still do not read BluRay discs, but rather still use CD-ROM and DVD-ROM technology, despite the fact that there were available, although never commercialized, high capacity compact disc technology having a much smaller size. The appearance of BluRay discs, when CD-ROM and DVDROM had already been commercialized for a considerable time was responsible to comprise the development of high capacity and smaller size compact discs. On the side of information technology, USD storage (types 1.0, 2.0 and finally 3.0) appeared keeping compatibility with previous versions. Finally, it is becoming more and more generalized the use of "cloud" storage. Nevertheless, the big multinationals of entertainment and information technology did not have these technologies to compete with each other but rather, as far as it was possible, they made them complementary. Remember that the DVD-DOM was being commercialized for a long period of time before BluRay discs appeared and even today BluRay dics reading computers have not been produced (although they do read CD-ROM and DVD-ROM).

Consequently, wealth and technology concentration in a few hands should not appear to be strange, since it is a natural response of capitalism to technological acceleration.

\section{The Disruption Created by AI}

AI is the substitution of labor for capital, and it constitutes the ultimate way in which capital destroys labor [8].

"Karl Marx was right: the inevitable struggle between capital (whose interests are promoted by management) and labor force is a losing proposition for workers. What he didn't fully appreciate is that we're all workers, even managers, doctors, and colleague professors" [9], pp. 10-11.

AI can essentially be classified in two types: synthetic intellects and forged 
workers [9]. Although the increasingly more spectacular achievements of AI on occasion opens the door for the production of new goods and services, in most cases they tend to replace human labor.

The economy is like a scissor that requires two sharpened blades in order to function properly: the supply side and the demand side. Clearly, the gradual but inevitable incorporation of AI to the economic system increases the ability of capital to produce goods and services, but it leaves apart labor, whose income are responsible of the demand side and precisely allow the system to survive. If AI produces all or almost all of the goods and services, but there is nobody with a job in order to be able to make money, who is going to buy these goods and services? This is precisely the new problematic facing capitalism today, and it is crucial. The lack of jobs (or low-quality jobs) and low growth in the economies typical of these times are signs that this problematic is becoming more and more important.

\section{How to Solve the Problematic?}

This theory holds that the value of the labor paid constitutes, as a matter of fact, the true value of economic systems. Thus, if we wish to grow the economy, the payments due to labor need to be increased. But simply increasing the minimum wage does not work, because, sooner or later, the inflation consumes what has been gained. Furthermore, such salary increase is not justified by an equivalent (and tied to) increase in the production of goods and services, so that the results is, precisely, inflation.

As a consequence, AI must be considered as a tool that increases the productivity of labor (of all kinds, manual and intellectual), since it is necessary to give the labor force the opportunity to continue making the same amount of money working less time, because working less time and the successful application of AI to labor environments allows to maintain and even increase the production of goods and services. In this way two objectives are accomplished: the first and foremost is to avoid reducing the value of labor, which, according to the theory here exposed, is the true value of the economy. The second is to give workers slack time so that they devote it to whatever seems to be for them more favorable. Some families, or members of the family, will choose to interact more with their families. But others could use the additional leisure time preparing themselves in those changing skills that the new workforce environments demand, being able not only to be more productive, but also obtaining other jobs. If labor hours are reduced from eight hours to four hours maintaining or even increasing productivity, the value of the economy would tend to be duplicated.

Combining the latter, in some cases, with some forms of stock ownership of the corporation people work for is, precisely, the solution to the systemic and catastrophic problematic imposing the implementation of $\mathrm{AI}$ in the economy.

There is also another alternative, although in my view perhaps not so adequate. It is possible to establish a labor insurance system, such that, when some- 
one working in the formal economy loses his or her job, the insurance (maybe called a labor mortgage) would pay the base salary in compensation for the salary that will be gained in the future, once the person manages to position himself or herself in the labor market. Perhaps the worker requires to acquire new skills in the case of the traditional workforce or the entrepreneur needs to gather new impulse to launch into the market a new good or service. The problem with this kind of measures is that they either depend on insurance companies, which clearly are a business, so that they always need to make more money than they spend, or the government would take care of the cost (as it would be the case for a monthly payment to all of the inhabitants of any given economic area), the latter also being problematic in an era in which world governments are seeing their forces and capabilities reduced.

On the other hand, as a means to give the ideas of Kaplan [9] with respect to organizations (being physical, virtual such as a web page, or a combination of both) promoting the education of people according to the skills demanded by companies an opportunity, it is simply a matter of leaving the initiative to private companies, such as https://udacity.com/, which offers certified and specialized technical education according to current needs promoting such education.

\section{Discussion}

In hindsight, for the near future, it becomes clear, due to the ever-increasing abilities and complexity of synthetic intellects and forged workers, the possibility of substituting work, traditionally carried out by people, to work carried out by AI. In the extremes of the skills required for different types of jobs in the labor market there seem not to exist immediate problems. For example, on the one hand are artisans making artistic works with a high level of detail in imbued creativity only possible, for the moment, by minds and human hands working combined. On the other hand, there are the intellectual labors requiring a high degree of creativity that cannot be systematized, such as the innovation in the way to portray things, as is the case of planning the future of organizations and society and other activities requiring the combination of creativity and labor like the professor in the classroom constantly improving classes. But in the middle of this spectrum of labor skills there are countless jobs that are candidates for systematization and automation using AI having new and increasing skills. For example, one could think that the work or a lawyer is immune to automation using AI, but it is not so. With current technology, and applying the legal equivalent of a Watson system by $\mathrm{IBM}^{1}$, it is possible to set up a web page that interactively retrieves legal needs and specific data for the case being required for the elaboration of a contract or legal license and let a synthetic intellect complex enough to formulate such contract or legal license required by the customer. In order to ensure the quality of the job, a human lawyer could review the resulting contract

${ }^{1}$ Watson of IBM won the Jeopardy contest against the human champion in a widely covered and televised event in 2011. 
or license, but the labor or the lawyer could be made much more productive. In this sense, suppose that a professional human lawyer working eight hours per day is able to write four contracts or licenses. Alternatively, a synthetic intellect equipped with the best machine learning technology could write, at least, ten contracts or licenses in eight hours. In this case, the lawyer would be delegated to the work of reviewing the contract or license written by the synthetic intellect, which requires much less time and a valuation of his or her work apparently lower. However, the correct solution to this problematic is not to reduce the working hours of the lawyer to four hours and the salary to the half, but rather, on the contrary, to maintain the same payment for a working schedule having four hours. In this way, the synthetic intellect would write five contracts or licenses in four hours being reviewed by the lawyer. This increases the productivity of the system by $25 \%$ without affecting the payment to the lawyer while at the same time reducing his or her working hours to the half, without reducing the productivity of the economic system, but rather increasing it. If another lawyer is hired to work four additional hours with the same synthetic intellect (or the salary of the same lawyer is duplicated to work in two shifts of four hours each) ten contracts would be produced in eight hours. Now, paying twice the salary, two and a half more contracts or licenses are produced. Notice that requesting ten contracts in eight hours should be no problem for the synthetic intellect, since the same web page could accommodate several customers at the same time and the writing work for the synthetic intellect should be fast. Nevertheless, the bottleneck is in the human worker who would have to review ten contracts or licenses in eight hours, which could be too much to ask for. Increasing the productivity of the system $250 \%$ constitutes incentive enough for investors so that they invest in the required AI (remember that salary paid only doubles). In this way inflation is not generated, since there is an increment in productivity and at the same time the purchasing power of people increases, which will inevitably result in duplicating the size of the economy and substantially increasing the quality of life of the lawyer. A number of other examples can be considered.

There is a different line of reasoning that leads to different conclusions. Suppose there is a landlord owing five hundred hectares of very productive land. This landlord hires temporal workers during the busy seasons. Even if one thousand temporal workers are hired during each busy season, it is expected there is already a considerable degree of automation being used in the property of the landlord. Even more, the salary paid to these temporal workers would be relatively low compared to the investments made and operational costs required. In that case, the incentives to more AI automation would not come from saving labor costs, but rather from increasing the productivity of the land. Although some workers may not only maintain but even improve their working conditions, being hired as experts in land management, $\mathrm{AI}$ automation would lead to the direct replacement of manual workers, keeping only the ones that are indispensable. 
In contrast to the typical recommendation derived from this work, simply increasing the minimum wage would be counterproductive, since the employer, when having to pay more for the same work, would simply reallocate the additional cost paid in wages to the price of the good or service being considered, which tends to generate inflation in the economy, thus cancelling the increase in the minimal wage.

Although it is expected the basic ideas here proposed should solve the most immediate contradictions of capital, it is not a recipe that will work forever. Remember that the application of Keynesianism [10] after the Second World War worked nicely during the 1950s and 1960s, but it started showing exhaustion during the 1970s [11]. During the 1980s neoliberalism had been imposed [12] and it has continued its course leading the world to catastrophe unless new considerations are made.

However, there surely are limits to the application of the recipe of reducing working hours in order to save the system. Sooner or later the model here proposed would be exhausted. Then a new approach will be required. From a philosophical point of view the idea is to reinforce the supply side for a while (neoliberalism) and then the demand side (a strategy here called neolaborism) and thus repeating the cycle over and over, in such way that the double edge of the "scissors" of the economy continues to work properly. Notice that, since the 1980s, with the application of neoliberalism, the ability of the economies to produce goods and services has been improved. However, the Cold War is over and today there are a number of manufacturing facilities working at a fraction of their capacity, which indicates that the supply side of the economy has already been strengthened. It seems now necessary to strengthen the demand side. Neolaborism constitutes a simple theory, but also a tool of economic policy, allowing with measures that are relatively simple to implement to strengthen the demand side of the economy.

Since the 1970s the median of salaries in real prices (without inflation) has been maintained and has not increased since then [2].

\section{Conclusions}

The essential difference between the income poured into the economy as a result of labor costs, unlike the work performed by machines, is that human labor continues to generate economic activity in the form of salaries and profit, while the work performed by AI only creates economic activity when acquiring such machinery (and in any case when updating the technology or repairing it) and not at all times.

The key of the ideas presented here is to be able to increase the value of the salaries paid in any given economy for the labor carried out while at the same time increasing the productivity due to the successful application of AI at least in the same degree. 


\section{References}

[1] Ricardo, D. (1817/1951) On the Principles of Political Economy and Taxation. In: Sraffa, P., Eds., Works and Correspondence of David Ricardo, Volume I. Cambridge University Press.

[2] Stiglitz, J.E. (2013) The Price of Inequality: How Today's Divided Society Endangers our Future. W. W. Norton \& Company. https://doi.org/10.1111/npqu.11358

[3] Friedman, M. (2002) Capitalism and freedom. The University of Chicago Press. https://doi.org/10.7208/chicago/9780226264189.001.0001

[4] Copertari, L.F. (2017) Cuando la tecnología nos alcance: Inevitablemente la Inteligencia Artificial Superhumana llegará. La pregunta es: ¿estaremos preparados?. Editorial Académica Española.

[5] Kurzweil, R. (2005) The Singularity Is Near: When Humans Transcend Biology. Penguin Books.

[6] Varoufakis, Y. (2015) Capitalism Will Eat Democracy-Unless We Speak Off. http://www.ted.com

[7] Marx, C. (1867/1946) El capital: Crítica de la economía política (tomos I, II y III). Fondo de Cultura Económica.

[8] Harvey, D. (2014) Seventeen Contradictions and the End of Capitalism. Oxford University Press.

[9] Kaplan, J. (2015) Humans Need Not Apply: A Guide to Wealth \& Work in the Age of Artificial Intelligence. Yale University Press.

[10] Keynes, J.M. (1936) The General Theory of Employment, Interest, and Money. John Maynard Keynes.

[11] Polanyi, K. (2001) The Great Transformation: The Political and Economic Origins of Our Time. Beacon Press.

[12] Harvey, D. (2005) A Brief History of Neoliberalism. Oxford University Press.

Submit or recommend next manuscript to OALib Journal and we will provide best service for you:

- Publication frequency: Monthly

- 9 subject areas of science, technology and medicine

- Fair and rigorous peer-review system

- Fast publication process

- Article promotion in various social networking sites (LinkedIn, Facebook, Twitter, etc.)

- Maximum dissemination of your research work

Submit Your Paper Online: Click Here to Submit

Or Contact service@oalib.com 